\title{
Properties of Activated Carbon Blacks Filled SBR Rubber Composites
}

\author{
Geyou Ao, Quanli Hu and Myung-Soo Kim^ \\ Department of Chemical Engineering, Myongii University, Yongin, Gyonggi-do 449-728, Korea \\ ^e-mail: myungkim@mju.ac.kr \\ (Received May 3, 2008; Accepted June 5, 2008)
}

\begin{abstract}
Rubber reinforcing carbon black N330 was treated by physical activation under $\mathrm{CO}_{2}$ to different degrees of burn-off. The mechanical properties indicating the reinforcement of SBR (Styrene-Butadiene Rubber) vulcanizates filled by activated carbon blacks, such as tensile strength, modulus at 300\% strain and elongation at break were determined. During $\mathrm{CO}_{2}$ activation of fresh carbon blacks, the development of microporous structure caused an increase of extremely large specific surface area and the porosity turned out to be an increasing function of the degree of burn-off. The tensile strength and modulus at $300 \%$ of activated carbon blacks filled rubber composites were improved at lower loading ratios of $20 \mathrm{and} 30 \mathrm{phr}$, but decreased drastically after $30 \mathrm{phr}$, which is considered that it might be difficult to get a fully dispersed rubber mixture at higher loading ratios for fillers having very large specific surface areas. However, the Electromagnetic Interference (EMI) shielding effectiveness of SBR rubber composites having activated carbon black at $74 \%$ yield were improved at a large extent when compared to those having raw carbon black and increased significantly as a function of increasing loading ratio.
\end{abstract}

Keywords : Carbon black, $\mathrm{CO}_{2}$ activation, Rubber reinforcement, EMI shielding effectiveness

\section{Introduction}

Carbon black is a widely used solid carbon material as a filler to enhance the performance of rubbers and other polymeric materials. The reinforcement of elastomers by particulate fillers has been studied in depth in numerous investigations, and it is generally accepted that this phenomenon is, to a large extent, dependant on the physical interactions between the filler and the rubber matrix [1]. It is well known that the structure, surface characteristics and especially particle size of the fillers are the main factors that determine their reinforcing effects in composites [2].

In order to have a good adhesion between filler and polymer, surface treatments are therefore needed to improve the wettability of carbon surfaces by promoting the formation of hydrophilic groups, which increase the surface energetics [3]. In general, for the activation of carbon materials, non-graphitizable carbons which are more disordered can be activated physically in stream or $\mathrm{CO}_{2}$, whereas the more ordered graphitizable carbons require chemical activation for the generation of porosity [4].

Another application of carbon black is to incorporate polymer matrices with it to act as an electrically conductive filler to improve the conductivity and EMI shielding effectiveness of polymers. An electromagnetic shielding material is a material that weakens radiated electromagnetic energy. Although the use of polymers for housing the electronic device is popular due to their light weight, flexible and less expensive characteristics when compared to metal, polymers are electrically insulating and transparent to electromagnetic radiation i.e. their inherent EMI shielding effectiveness is practically zero. Other electrically conductive fillers include graphite fibers, metal fibers and metal particulate [5].

In the present work, various properties of carbon blacks after being treated by $\mathrm{CO}_{2}$ activation and their SBR rubber composites were characterized to find out the effect of different degrees of physical activation on the reinforcing and EMI shielding effectiveness of carbon black fillers when mixed with rubber composites.

\section{Experimental}

\section{1. $\mathrm{CO}_{2}$ activation of raw carbon black}

The samples denoted by $\mathrm{N} 330-\mathrm{f}-\mathrm{CO}_{2}$ with different percentage yields were $\mathrm{CO}_{2}$ activated raw N330 fluffy (N330-f) blacks which were obtained from DC Chemical. Co., Ltd.. Activated carbon blacks were prepared by placing raw N330-f black into a horizontal cylindrical furnace (80 mm diameter, Super Kanthal Tube Furnace) under flowing nitrogen $(100 \mathrm{ml} / \mathrm{min})$. For all activations, approximately $40 \mathrm{~g}$ of raw carbon blacks were used. The furnace was purged with flowing nitrogen $(100 \mathrm{ml} / \mathrm{min})$, and the temperature was increased at a constant rate $10^{\circ} \mathrm{C} / \mathrm{min}$ until the desired activation temperature from 950 to $1000^{\circ} \mathrm{C}$. Once the activation temperature was reached, nitrogen flow 
Table 1. Compounding formulations

\begin{tabular}{cc}
\hline Ingredients & Loading [phr] \\
\hline Rubber $^{\mathrm{a}}$ & 100 \\
Carbon blacks $^{\mathrm{b}}$ & $0 \sim 60$ \\
Zinc oxide & 5 \\
Stearic acid $^{\mathrm{d}}$ & 2 \\
Dispersive agent $^{\mathrm{c}}$ & 3 \\
Accelerator $^{\mathrm{d}}$ & 1 \\
Sulfur $^{\mathrm{a}}$ & 2 \\
\hline
\end{tabular}

${ }^{a}$ Styrene Butadiene Rubber (SBR-1502).

${ }^{b} \mathrm{~N} 330-\mathrm{f}$ before and after surface modification.

cEF44.

${ }^{\mathrm{N}} \mathrm{N}-\mathrm{Oxydiethylene-2-benzothiazolesulfenamide.}$

was switched to $\mathrm{CO}_{2}$ (from 400 to $700 \mathrm{ml} / \mathrm{min}$ ). Furnace temperature and $\mathrm{CO}_{2}$ flow were kept constant for $3 \mathrm{~h}$. At the end of the activation period, the sample was cooled under nitrogen $(100 \mathrm{ml} / \mathrm{min})$.

\subsection{Preparation of composites}

The compounding formulations of composites are reported in Table 1. Rubber chemicals such as $\mathrm{ZnO}$, sulfur and stearic acid were supplied by DAEJUNG Chemicals \& Metals Co., Ltd., Korea; EF44 and accelerator were collected from ILSHIN CHEMTECH Co., Ltd., Korea and TOKYO KK Co., Ltd., Japan, respectively. The blending was carried out in a Haake Rheomix 600 internal mixing system at $150^{\circ} \mathrm{C}$ for SBR rubbers which were provided by Kumho Petrochemical Co., Korea under identical conditions of processing (mixing time $=26 \mathrm{~min}$; rotor speed $=45 \mathrm{rpm}$ ). The filling level of the mixer chamber was $70 \%$. Before measuring the mechanical and electrical properties of composites, the filled SBR composites were cured at $1 \mathrm{MPa}$ and $145^{\circ} \mathrm{C}$ for $35 \mathrm{~min}$ under a CARVER hot press machine according to ASTM D 3185 .

\subsection{Characterization of carbon blacks and composites}

The specific surface area and porosity of carbon blacks were characterized by physical adsorption tests with a surface analyzer (Automatic Volumetic Sorption Analyser, Autosorb-1, Quantachrome) at $77 \mathrm{~K}$ having nitrogen as the adsorbate. The volume resistivity $(\Omega \mathrm{cm})$ of carbon black powder was tested by a digital multi-meter (Hioki Co., HI Tester 3540) keeping the carbon black sample under a constant pressure of 1,000 psi for about $20 \mathrm{~min}$ by a power press (ISE-WP 10T, Enerpac, USA). The microstructure and porous structure of carbon blacks were observed by Scanning Electron Microscope (SEM, 3500N, Hitachi Science System Ltd., Japan, Magnification: $\times 300,000)$ and Transmission Electron Microscope (TEM; JEOL $300 \mathrm{kv}$, JEOL Ltd., USA, Magnification: $\times 300,000)$. The surface chemistry of carbon blacks before and after $\mathrm{CO}_{2}$ activation was characterized by the attenuated total reflection-Fourier transform infrared (ATR-FTIR, Vertex 70, FT-IR with Raman/NIR, BRUKER) spectroscopy. The surface resistivity of rubber composites was tested by SIMCO TRUSTAT Worksurface TESTER (Moder ST-3) with testing range in $10^{4} \sim 10^{12} \Omega / \mathrm{sq}$. For composites having low surface resistivity, they were measured by a four-probe technique (Chang Min Co., LTD.). The mechanical properties of composites were determined by a UTM machine (LLOYD LR5K) at room temperature with a crosshead speed of $500 \mathrm{~mm} / \mathrm{min}$ under room temperature according to ASTM standards. The EMI shielding effectiveness of the rubber composites filled by various fillers was measured using a shielding measurement system (Hewlett-Packard Co., HP-8720C) according to the method described in ASTM D4935.

\section{Results and Discussion}

\subsection{Properties of $\mathrm{CO}_{2}$-acitvated carbon blacks}

Mesopore, micropore volumes, BET surface areas and powder resistivity of various activated carbon blacks are reported in Table 2. During $\mathrm{CO}_{2}$ activation, the enlargement of pore diameters and development of microporous structures were introduced in the carbon blacks, resulting in extremely large specific surface areas which were in the range of $394 \sim 724 \mathrm{~m}^{2} / \mathrm{g}$. The mesopore and micropore

Table 2. Properties of N330-f carbon blacks treated by $\mathrm{CO}_{2}$ activation

\begin{tabular}{|c|c|c|c|c|c|c|}
\hline Sample & $\begin{array}{c}\text { Yield } \\
\%\end{array}$ & $\begin{array}{c}\text { Resistivity } \\
(\Omega \cdot \mathrm{cm})\end{array}$ & $\begin{array}{c}\text { Mesopore } \\
\text { volume } \\
\left(\mathrm{cc} \cdot \mathrm{g}^{-1}\right)\end{array}$ & $\begin{array}{c}\text { Micropore } \\
\text { volume } \\
\left(\mathrm{cc} \cdot \mathrm{g}^{-1}\right)\end{array}$ & $\begin{array}{c}\text { Total pore } \\
\text { volume } \\
\left(\mathrm{cc} \cdot \mathrm{g}^{-1}\right)\end{array}$ & $\begin{array}{c}\text { BET } \\
\left(\mathrm{m}^{2} \cdot \mathrm{g}^{-1}\right)\end{array}$ \\
\hline Raw N330-f & 100 & 0.0744 & 0.10406 & 0.03667 & 0.14073 & 80 \\
\hline DCC-N330-f- $\mathrm{CO}_{2}\left(950^{\circ} \mathrm{C} 400 \mathrm{sccm} 3 \mathrm{hr}\right)$ & 74 & 0.0813 & 0.3205 & 0.2094 & 0.5299 & 394 \\
\hline DCC-N330-f-CO $\left(950^{\circ} \mathrm{C} 700 \mathrm{sccm} 3 \mathrm{hr}\right)$ & 72 & 0.0680 & 0.2826 & 0.2105 & 0.4931 & 421 \\
\hline DCC-N330-f- $\mathrm{CO}_{2}\left(970^{\circ} \mathrm{C} 650 \mathrm{sccm} 3 \mathrm{hr}\right)$ & 67 & 0.0652 & 0.3796 & 0.3026 & 0.6822 & 575 \\
\hline DCC-N330-f- $\mathrm{CO}_{2}\left(970^{\circ} \mathrm{C} 700 \mathrm{sccm} 3 \mathrm{hr}\right)$ & 66 & 0.0593 & 0.4201 & 0.2847 & 0.7048 & 573 \\
\hline DCC-N330-f- $\mathrm{CO}_{2}\left(1000^{\circ} \mathrm{C} 400 \mathrm{sccm} 3 \mathrm{hr}\right)$ & 62 & 0.0753 & 0.4219 & 0.3019 & 0.7238 & 582 \\
\hline DCC-N330-f-CO ${ }_{2}\left(1000^{\circ} \mathrm{C} 700 \mathrm{sccm} 3 \mathrm{hr}\right)$ & 57 & 0.0667 & 0.4331 & 0.4006 & 0.8337 & 724 \\
\hline
\end{tabular}




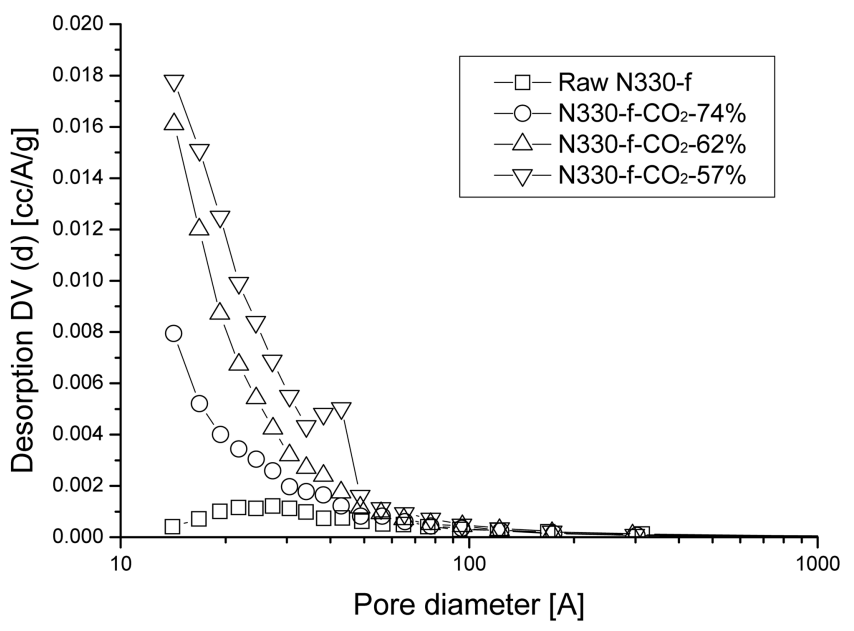

Fig. 1. Pore size distribution of N330-f before and after $\mathrm{CO}_{2}$ activation at different conditions.

volumes of activated carbon blacks indicated that these porosities were an increasing function of the degree of burnoff. It was known that as the specific surface area of activated carbon blacks increased, there would be difficulty in forming continuous electric network in the voluminous carbon black samples due to the decreased density. However, the measured powder resistivity of activated carbon blacks were similar to each other upon keeping under constant pressure of $1,000 \mathrm{psi}$ by a power press.

Fig. 1 shows the pore structure of activated carbon blacks which was characterized in terms of pore size distribution illustrating the surface heterogeneity of porous solids. In general, microporosity in carbons is created by removal of solid material by an activation process. However, after the evolution of microporosity to certain optimum degree, further activation to increase the microporosity is accompanied by mesopore and macropore evolution [6]. As in Fig. 1 , with further activation up to $57 \%$ yield, the largest amount of mesopores had been developed when compared to other activated carbon blacks.

In Fig. 2, from high resolution TEM images, it can be seen clearly that at further activation with $57 \%$ yield, carbon black developed more pores than that at lower degree of activation. After $\mathrm{CO}_{2}$ activation, the increased amount of

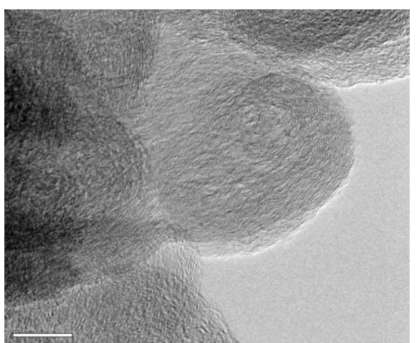

(a)

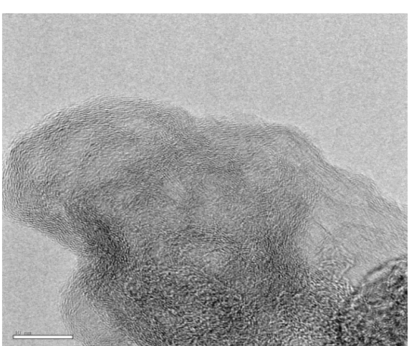

(b)
Fig. 2. HR-TEM images of (a) N330-f- $\mathrm{CO}_{2}-74 \%$ and (b) N330$\mathrm{f}-\mathrm{CO}_{2}-57 \%(\times 300,000)$.

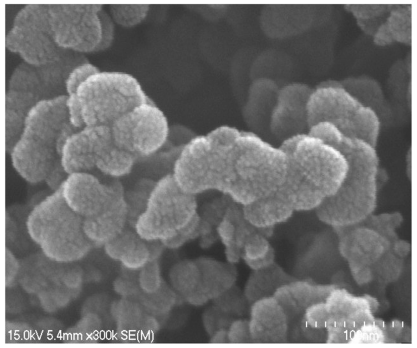

(a)

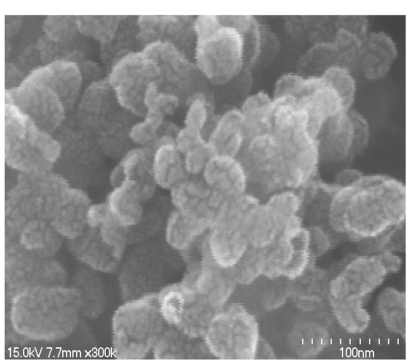

(b)
Fig. 3. SEM images of (a) raw N330-f and (b) N330-f-CO $74 \%(\times 300,000)$.

surface disorder of carbon black fillers played a major role for the filler-polymer interaction. In carbon black filled elastomers, the contribution to reinforcement on small scales can be attributed to the complex structure of the branched filler aggregates as well as to a strong surface polymer interaction, leading to the bound rubber [7]. The SEM images of carbon blacks before and after $\mathrm{CO}_{2}$ activation show that activated carbon black with $74 \%$ yield exhibited more heterogeneous surface than raw carbon black, having much different particle sizes (Fig. 3).

Surface functional groups of various activated carbon blacks are shown in Fig. 4 of the ATR-FTIR spectra which were corrected by removing the spectral contributions due to atmospheric water. The strong peak at $1750 \mathrm{~cm}^{-1}$ of carbon blacks before and after $\mathrm{CO}_{2}$ activation can be seen, which indicates the presence of $\mathrm{C}=\mathrm{O}$ functional groups characterized by aldehydes, ketones, carboxylic acids and esters. All carbon black samples also present two peaks at 1000 and $830 \mathrm{~cm}^{-1}$. The peak at $1000 \mathrm{~cm}^{-1}$ can be assigned to the $\mathrm{C}-\mathrm{H}$ bending of alkenes and the peak at $830 \mathrm{~cm}^{-1}$ is the $\mathrm{C}-\mathrm{H}$ bending of aromatic rings in carbon blacks. In general, chemical bonds such as $\mathrm{C}=\mathrm{O}, \mathrm{C}=\mathrm{C}$, and aromatic rings of carbon blacks cracked as an increasing function of

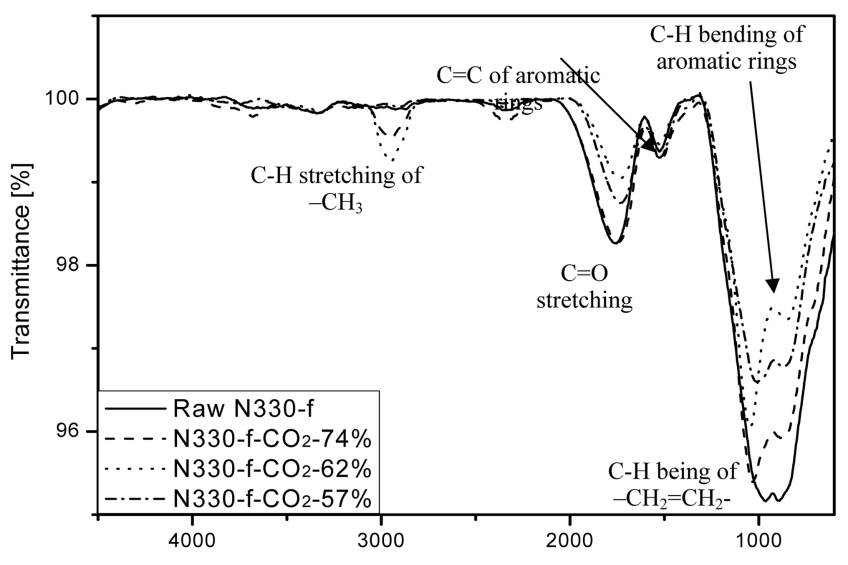

Wavenumber $\left[\mathrm{cm}^{-1}\right]$

Fig. 4. ATR-FTIR spectra of N330-f before and after $\mathrm{CO}_{2}$ activation at different conditions. 


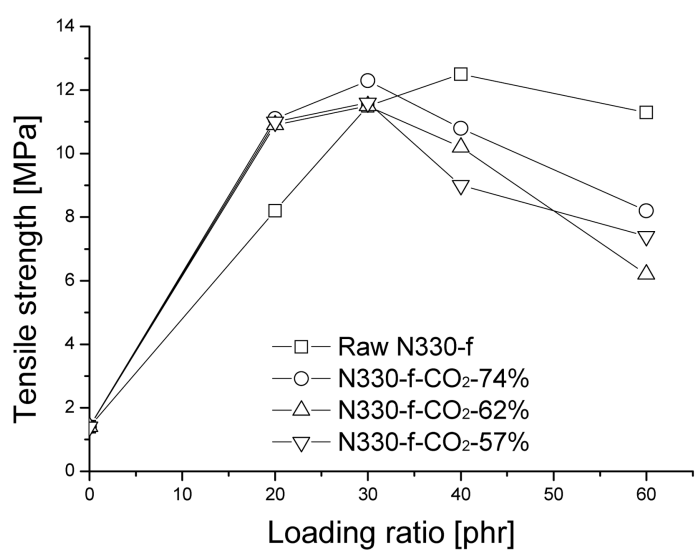

(a) tensile strength

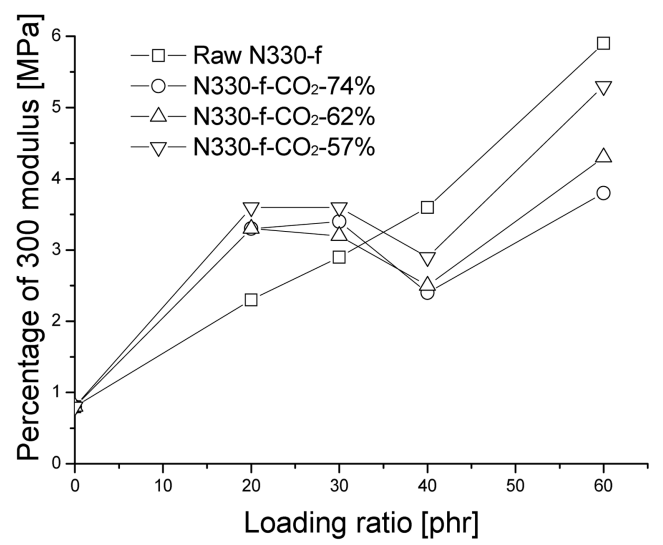

(b) modulus at $300 \%$

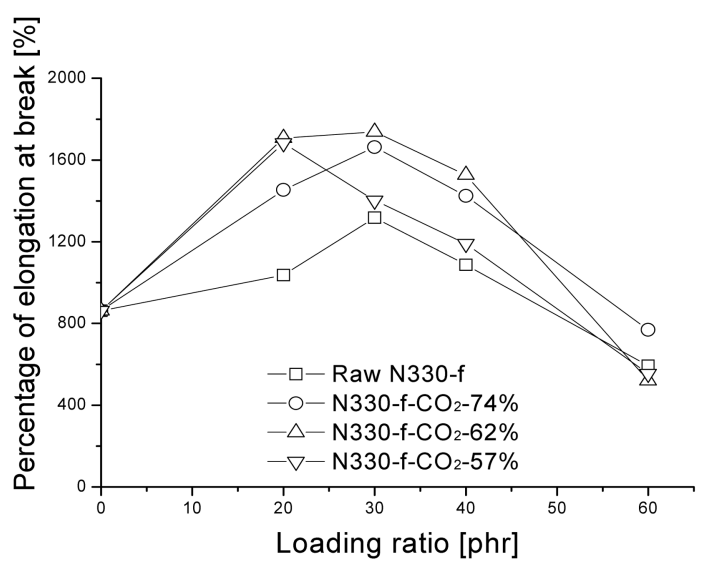

(c) elongation

Fig. 5. Mechanical properties of SBR rubber composites as a function of loading ratio (SBR filled by raw N330-f and N330-f-CO with different activation conditions).

the degree of burn-off, leading to a subtle increase of C-H stretching of $-\mathrm{CH}_{3}$. As we know that, the chemical groups on the surface are related to surface activity, which is a poorly defined term, but widely used in the filler filed as a reinforcing parameter. Although variations in surface energy determine the capacity and energy of adsorption, no direct correlation has been demonstrated between chemical groups on the carbon black surface and rubber related properties. In the case of carbon black, the filler-polymer interaction is mainly of physical nature (physisorption) [8].

\subsection{Mechanical properties of composites}

Carbon black structure gives rise to reinforcing effects and therefore the aggregate is the smallest form of a given carbon black grade well dispersed in an elastomer that will still keep all the reinforcing capabilities of the filler. Carbon black aggregates usually contain internal voids which are capable of absorbing polymer and partially shielding it from stress when the rubber matrix is deformed [9].

Fig. 5 illustrates variations of mechanical properties of SBR rubber composites having carbon blacks after $\mathrm{CO}_{2}$ activation at different loading ratios. In general, the tensile strength and modulus at $300 \%$ strain values of rubber composites reinforced by activated carbon blacks were similar with each other. More specifically, SBR rubber composites filled by activated carbon blacks at $74 \%$ yield showed better tensile strength than those having further activated ones. However, with increasing degree of burn-off up to the $57 \%$ yield, the corresponding rubber composite exhibited the highest value of modulus at $300 \%$ strain when compared to other activated carbon blacks filled rubber composites.

As a whole, the mechanical properties of rubber 
Table 3. Surface resistivity of SBR rubber composites as a function of loading ratio

\begin{tabular}{ccccc}
\hline $\begin{array}{c}\text { Loading } \\
\text { Ratio } \\
\text { Sample }\end{array}$ & $20 \mathrm{phr}$ & $30 \mathrm{phr}$ & $40 \mathrm{phr}$ & $60 \mathrm{phr}$ \\
\hline Raw N330-f & $*$ & $*$ & $(5.43 \pm 0.82) \mathrm{E}+06$ & $(2.51 \pm 0.38) \mathrm{E}+04$ \\
$\mathrm{~N} 330-\mathrm{f}-\mathrm{CO}_{2}-74 \%$ & $*$ & $(1.98 \pm 0.34) \mathrm{E}+05$ & 4778 & 310 \\
$\mathrm{~N} 330-\mathrm{f}-\mathrm{CO}_{2}-62 \%$ & $(3.00 \pm 0.98) \mathrm{E}+08$ & $(3.52 \pm 0.63) \mathrm{E}+04$ & 1867 & 90 \\
$\mathrm{~N} 330-\mathrm{f}-\mathrm{CO}_{2}-57 \%$ & $(2.89 \pm 0.96) \mathrm{E}+05$ & 1775 & 188 & 40 \\
\hline
\end{tabular}

*The resistivity is larger than $1.00 \mathrm{E}+12 \Omega / \mathrm{sq}$.

composites having activated carbon black fillers were improved at lower loading ratio of 20 and $30 \mathrm{phr}$ as compared to that having raw carbon black due to the more developed surface heterogeneity of carbon blacks after $\mathrm{CO}_{2}$ activation, which increased the degree of adhesion between carbon blacks and SBR rubber to a certain extent. This indicates that in this range of loading ratios, activated carbon blacks at $57 \% \sim 74 \%$ yields were applicable to be further used as reinforcing fillers to the rubber. But the mechanical properties decreased drastically after $30 \mathrm{phr}$ loading except that the modulus at $300 \%$ increased significantly again at $60 \mathrm{phr}$ loading. Thus it was considered that although the carbon black dispersion into the rubber matrix was improved to a certain level at lower filler loading ratios due to the increased specific surface area after activation, with further loading of carbon blacks, it turned out to be that it might be difficult to get a fully dispersed rubber mixture for fillers whose specific surface areas were extremely large. As the carbon black loading is increased, it makes additional black surface available for polymer attachments. When the loading level is reached to a limit value, the carbon black does not act as a reinforcing filler [10]. Concerning the modulus at $300 \%$ of activated carbon blacks filled rubber composites which was increased drastically again at $60 \mathrm{phr}$, it can be explained that this was caused by the much increased toughness of the rubber composites but at the same time they became more brittle.

\subsection{EMI shielding effectiveness of composites}

Table 3 shows the surface resistivity of SBR rubber composites having carbon black fillers before and after $\mathrm{CO}_{2}$ activation. While it is a common phenomenon that the electrical resistivity of rubber composites decreased drastically after the percolation concentration of carbon black fillers, activated carbon blacks filled rubber composites showed much less surface resistivity than those filled by raw carbon blacks. This may due to the more disordered surface of carbon blacks after activation which can form a better continuous conductive filler network in the rubber matrix. Further, the higher the degree of activation, the lower the surface resistivity of rubber composites.

Fig. 6 illustrates that the EMI shielding characteristics of carbon black/rubber composites increased as a function of filler loading due to increasing surface conductivity. The network formed due to distribution of conducting filler inside rubber matrices behaves like conducting mesh, which intercepts electromagnetic radiation [5]. As a result, the rubber composite filled by activated carbon black with $74 \%$

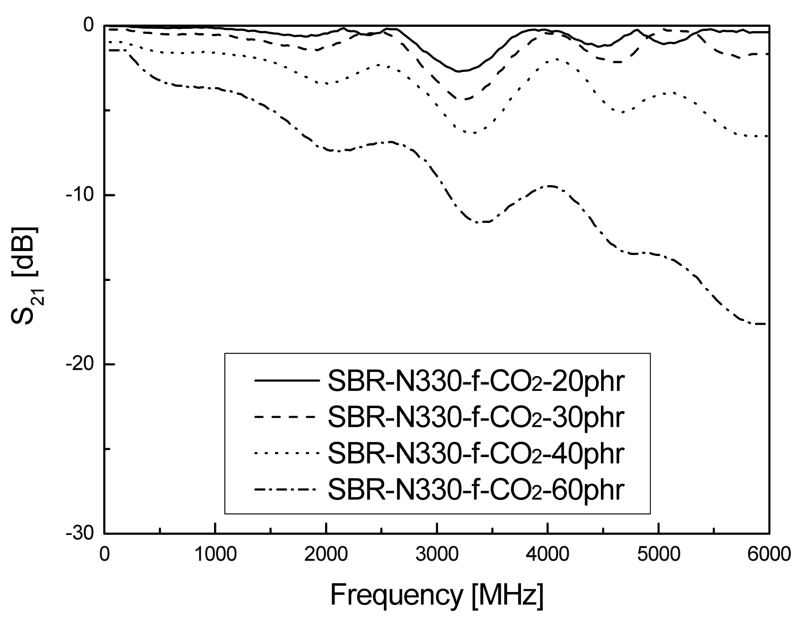

(a)

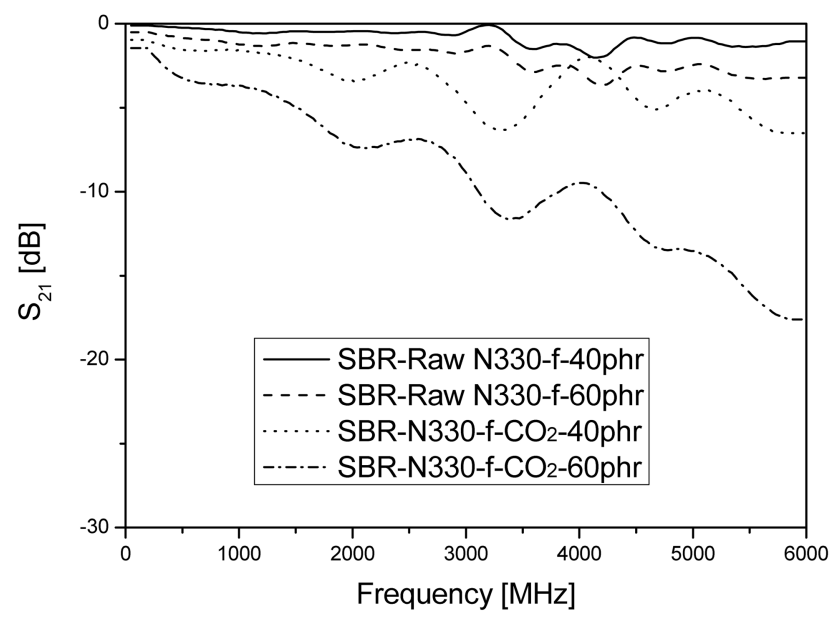

(b)

Fig. 6. Transmitted power density in EMI shielding as a function of frequency measured in the $0-6000 \mathrm{MHz}$ range of (a) SBR rubber composites having activated carbon black with $74 \%$ yield at various loading and (b) SBR composites having raw carbon black and activated carbon black with $74 \%$ yield at $40 \mathrm{phr}$ and $60 \mathrm{phr}$ loading ratio. 
yield with high surface conductivity showed much improved EMI shielding effectiveness at $60 \mathrm{phr}$ loading whose transmitted power density was the lowest and decreased progressively with increasing frequency range $0-6000 \mathrm{MHz}$ when compared to rubber composites having raw carbon black. However, electrical conductivity is not the scientific criterion for shielding, as conduction requires connectivity in the conduction path (percolation in case of a composite material containing a conductive filler). Although shielding does not require connectivity, it is enhanced by connectivity [11].

\section{Conclusions}

The effect of physical activation under $\mathrm{CO}_{2}$ on rubber reinforcing carbon blacks has been studied by means of surface heterogeneities including porosity, specific surface area and functional groups of carbon blacks surfaces; the corresponding mechanical properties of the various activated carbon blacks filled SBR rubber composites were also investigated. With physical activation the porosity of resulting carbon blacks were turned out to be an increasing function of the degree of burn-off, leading to an increase of extremely large specific surface areas. Surface functional groups of carbon blacks were changed including $-\mathrm{CH}_{2}=$ $\mathrm{CH}_{2}-, \mathrm{C}=\mathrm{O}$ bonds and aromatic rings cracking after $\mathrm{CO}_{2}$ activation, resulting in a little increase of $\mathrm{C}-\mathrm{H}$ stretching of $-\mathrm{CH}_{3}$, which may cause variations in surface energy determining the capacity and energy of adsorption. However, it was considered that the strong carbon black-rubber interaction is not necessarily result from chemical reactions involving chemical groups at the surface of carbon blacks, but from the strong physical interaction between the filler and polymer.

As to mechanical properties of rubber composites, activated carbon blacks with different yields showed similar reinforcing effect on the SBR rubber and they were improved to a certain degree at lower filler loading ratio 20 and $30 \mathrm{phr}$ as comparison to those filled by raw carbon blacks. But the mechanical properties of activated carbon blacks filled rubber composites were decreased significantly after $30 \mathrm{phr}$ due to the difficult dispersion problem of fillers having high contents in the rubber matrix. The experimental results of EMI shielding characteristic of SBR rubber composites indicated that with increasing carbon black loading, the shielding effectiveness was also increased. Further, the highest EMI shielding effectiveness was obtained for the rubber composites having activated carbon black with $74 \%$ yield at $60 \mathrm{phr}$ loading which was caused by the formation of more developed continuous conductive filler network in the rubber matrix due to the extremely high specific surface area of the carbon black after $\mathrm{CO}_{2}$ activation.

\section{Acknowledgement}

The authors gratefully acknowledge the New \& Renewable Energy R\&D program of the Korea Ministry of Commerce, Industry and Energy (MOCIE) for their financial support.

\section{References}

[1] Hajji, P.; David, L.; Gerard, J. F.; Pascault, J. P.; Vigier, G. J. Polym. Sci. Polym. Phys. 1999, 37, 3172.

[2] Zhou, X. W.; Zhu, Y. F.; Liang, J. Materials Research Bulletin 2007, 42, 456.

[3] Park, S. J.; Seo, M. K.; Nah, C. J. Coll. Int. Sci. 2005, 291, 229.

[4] Dawson, E. A.; Parkes, G. M. B.; Barnes, P. A.; Chinn, M. J.; Pears, L. A.; Hindmarsh. C. J. Carbon 2002, 40, 2897.

[5] Das, N. C.; Khastgir, D.; Chaki, T. K.; Chakraborty, A. Composites: Part A 2000, 31, 1069.

[6] Bansal, R. C.; Donnet J. B.; Stoeckli F. “Active Carbon", Marcel Dekler, New York. 1988.

[7] Vilgis, T. A. Polymer 2005, 46, 4223.

[8] Frohlich, J.; Niedermeier, W.; Luginsland, H.-D. Composites: Part A 2005, 36, 449.

[9] Taylor, R. "Introduction to Carbon Technologies", ed. Marsh, H.; Heintz, E. A.; Rodríguez-Reinoso, F. University of Alicante, Spain, 1993, 185.

[10] Demirhan, E.; Kandemirli, F.; Kandemirli, M. Materials \& Design 2007, 28, 1326.

[11] Chung, D. D. L. Carbon 2001, 39, 279. 